\title{
Literacy: a cultural influence on functional left-right differences in the inferior parietal cortex
}

\author{
Karl Magnus Petersson, ${ }^{1,2,3,4,6}$ Carla Silva, ${ }^{4,5,6}$ Alexandre Castro-Caldas, ${ }^{7}$ Martin Ingvar ${ }^{2,4}$ and Alexandra Reis ${ }^{2,4,6}$ \\ ${ }^{1}$ Max Planck Institute for Psycholinguistics, PO Box 310, 6500 AH Nijmegen, the Netherlands \\ ${ }^{2}$ Cognitive Neurophysiology Research Group, Stockholm Brain Institute, Karolinska Institute, Stockholm, Sweden \\ ${ }^{3}$ F.C. Donders Centre for Cognitive Neuroimaging, Radboud University Nijmegen, the Netherlands \\ ${ }^{4}$ Cognitive Neuroscience Research Group, Departamento de Psicologia, Faculdade de Ciências Humanas e Sociais, Universidade \\ do Algarve, Faro, Portugal \\ ${ }^{5}$ Departamento de Física, Faculdade de Ciências e Tecnologia, Universidade do Algarve, Faro, Portugal \\ ${ }^{6}$ Centre for Intelligent Systems, Universidade do Algarve, Faro, Portugal \\ ${ }^{7}$ Institute of Health Sciences, Catholic University of Portugal, Lisbon, Portugal
}

Keywords: functional neuroimaging, illiteracy, inter-hemispheric differences, literacy, PET, structural MRI

\begin{abstract}
The current understanding of hemispheric interaction is limited. Functional hemispheric specialization is likely to depend on both genetic and environmental factors. In the present study we investigated the importance of one factor, literacy, for the functional lateralization in the inferior parietal cortex in two independent samples of literate and illiterate subjects. The results show that the illiterate group are consistently more right-lateralized than their literate controls. In contrast, the two groups showed a similar degree of left-right differences in early speech-related regions of the superior temporal cortex. These results provide evidence suggesting that a cultural factor, literacy, influences the functional hemispheric balance in reading and verbal working memory-related regions. In a third sample, we investigated grey and white matter with voxel-based morphometry. The results showed differences between literacy groups in white matter intensities related to the mid-body region of the corpus callosum and the inferior parietal and parietotemporal regions (literate > illiterate). There were no corresponding differences in the grey matter. This suggests that the influence of literacy on brain structure related to reading and verbal working memory is affecting large-scale brain connectivity more than grey matter per se.
\end{abstract}

\section{Introduction}

Acquiring reading and writing skills, as well as other cognitive skills, during formal education can be viewed as an institutionalized cultural process and is an important source of structured cultural transmission (Petersson \& Reis, 2006). The study of illiterate subjects and their matched literate controls provides one opportunity to investigate the effects of the interaction between neurobiological and cultural factors on the outcome of cognitive development and learning (Petersson et al., 2001). Alternative approaches related to cross-cultural variation have been explored, including the implications of transparent and nontransparent orthographies on brain function (Paulesu et al., 2000). During the acquisition of reading and writing skills, the child creates the ability to represent aspects of the phonological component of language by an orthographic representation and relate this to a visuographic input-output code. This is typically achieved by means of a supervised learning process (i.e. teaching) in contrast to natural language acquisition, which is largely a spontaneous, nonsupervised and self-organized acquisition process (Petersson, 2005, in press). It seems unlikely that specific brain structures have evolved for the

Correspondence: Dr Karl Magnus Petersson, ${ }^{1}$ Max Planck Institute for Psycholinguistics, as above.

E-mail: karl.magnus.petersson@fcdonders.ru.nl

Received 23 February 2007, revised 1 June 2007, accepted 18 June 2007 purpose of mediating reading and writing (Petersson et al., in press) Instead, it seems that these skills are supported by preadapted brain structures, that is, brain structures that have evolved to serve specific functions at the phylogenetic level but have come to serve as means for a different end at the ontogenetic level. Reading and writing, invented some 6000 years ago, evolved through cultural development and only recently became 'typical' human skills. In fact, these skills are still far from universal at the beginning of the 21 st century. At present, it is estimated that there are close to one billion illiterate individuals in the world and of these about two-thirds are women (UNESCO, 2003; www.portal.unesco.org), while the average educational level of literate individuals is only $\sim 3-4$ years of schooling (cf. Abadzi, 2003).

Aspects of language can be an object of meta-linguistic awareness: the intentional and explicit control over aspects of phonology, syntax, semantics and discourse. During their individual development, children gradually create explicit representations and acquire processing mechanisms that allow for reflecting and analysing different aspects of language and its use (Karmiloff-Smith et al., 1996). When children subsequently learn to read, this also has repercussions on the phonological representations of spoken language (Morais, 1993; Petersson et al., 2000, 2001; Ziegler \& Goswami, 2005). Building on an implicit foundation of phonological knowledge, learning to read involves both explicit and implicit processes; typically children 
initially learn grapheme-phoneme mappings explicitly after which they apply and continue to learn how phonology is mapped onto its written representation implicitly (Gombert, 2003; Ziegler \& Goswami, 2005; Petersson \& Reis, 2006).

A large number of neuropsychological studies of acquired reading and writing impairment (alexia and agraphia) describe neuroanatomic lesions most prominently centred on the parietotemporal region, including the inferior parietal cortex and the posterior portions of the superior temporal gyrus, thus suggesting that this region is important for mapping orthographic representations onto phonologic representations (Friedman et al., 1993). Ernest Weber suggested in 1904 that the left hemispheric language dominance might depend on the acquisition of reading and writing skills, and early attempts to address the issue in aphasic patients appeared to support this hypothesis (Cameron et al., 1971; Wechsler, 1976). Specific differences in cognitive processing between literate and illiterate aphasic subjects has been reported, in particular with respect to pseudoword repetition and verbal memory tasks (Coppens et al., 1998). In addition, Lecours (1989) has suggested that illiterate subjects are more likely to use processing networks that include right-hemisphere regions when performing language tasks (Coppens et al., 1998). Studies using various dichotic listening tasks have yielded mixed results (Coppens et al., 1998), though a reversal of ear advantage for phonetically similar words in illiterate subjects has been reported (Damásio et al., 1979). One possibility that may reconcile the various findings with respect to literacy and lateralization is that hemispheric lateralization is a regional rather then a global functional phenomenon and it might be the case that hemispheric differences are only detected in tasks taxing the specific processing capacity of a given region (i.e. task dependence). However, the mechanisms influencing hemispheric specialization and the consequent interhemispheric interaction are not well understood, and both genetic and environmental factors appear relevant (Thompson et al., 2001; Sommer et al., 2002). Functional lateralization has been shown to depend on several factors, including stimulus material (Kelley et al., 1998) and experimental task (Stephan et al., 2003), and a recent review concluded that hemispheric specialization for language is multifactorial and may depend on both task and brain region (Josse \& Tzourio-Mazoyer, 2004). However, it is well accepted that both hemispheres play a role in language processing (Friederici, 2002; Knecht et al., 2002) and computational modelling has indicated that several possible mechanisms can support hemispheric lateralization (Reggia \& Schulz, 2002).

In the present study we first re-investigated one sample of illiterate female subjects and their matched literate controls with respect to the lateralization of the inferior parietal region in two simple immediate verbal repetition tasks (Petersson et al., 2000). There are several principal reasons for focusing on the inferior parietal region (Fig. 1) in literate and illiterate subjects: functionally this region has been related to reading (Friedman et al., 1993; Horwitz et al., 1998; Shaywitz et al., 1998; Paulesu et al., 2000) as well as to phonological processing and verbal working memory (Baddeley, 2003; Vallar \& Papagno, 1995; Jonides et al., 1998; Becker et al., 1999), and recent neuroanatomic findings suggest that there are differences between literacy groups (Castro-Caldas et al., 1999) in the part of corpus callosum interconnecting the parietotemporal regions (Pandya et al., 1971; De Lacoste et al., 1985; Pandya \& Seltzer, 1986; Aboitiz et al., 2003; Zaidel \& Iacoboni, 2003). The result of this initial exploratory investigation, briefly reported in an abstract (Petersson et al., 1998) and here reported in its original form, showed a significant group difference (group $\times$ hemisphere interaction; a positive functional leftright difference in the literate group while the illiterate subjects showed a prominent negative left-right difference independent of whether the subjects repeated words or pseudowords). Given these findings, we investigated a second independent sample of illiterate female subjects and their matched literate controls in an attempt to replicate the original findings in another simple verbal task. This yielded similar results. Finally, and in order to make the connection with our previously reported structural findings (Castro-Caldas et al., 1999) more suggestive, we acquired high-resolution T1-weighted structural magnetic resonance imaging (MRI) data in a third sample for subsequent voxel-based morphometry (VBM) analyses of the grey and white matter in the two literacy groups. The results showed a significant white matter difference in the posterior third of the midbody region, replicating the findings of Castro-Caldas et al. (1999), and this difference in the corpus callosum was part of a larger white matter cluster extending into the white matter related to the inferior parietal regions bilaterally (literate $>$ illiterate).

\section{Materials and methods}

\section{The study population of southern Portugal}

The fishing village Olhão in southern Portugal, where all of our studies on illiteracy have been conducted, is socioculturally homogeneous and the majority of the population has lived most of their lives within the community. Mobility within the region has been limited and the main source of income is related to agriculture or fishing. Illiteracy occurs in Portugal because of the fact that 40 or 50 years ago it was

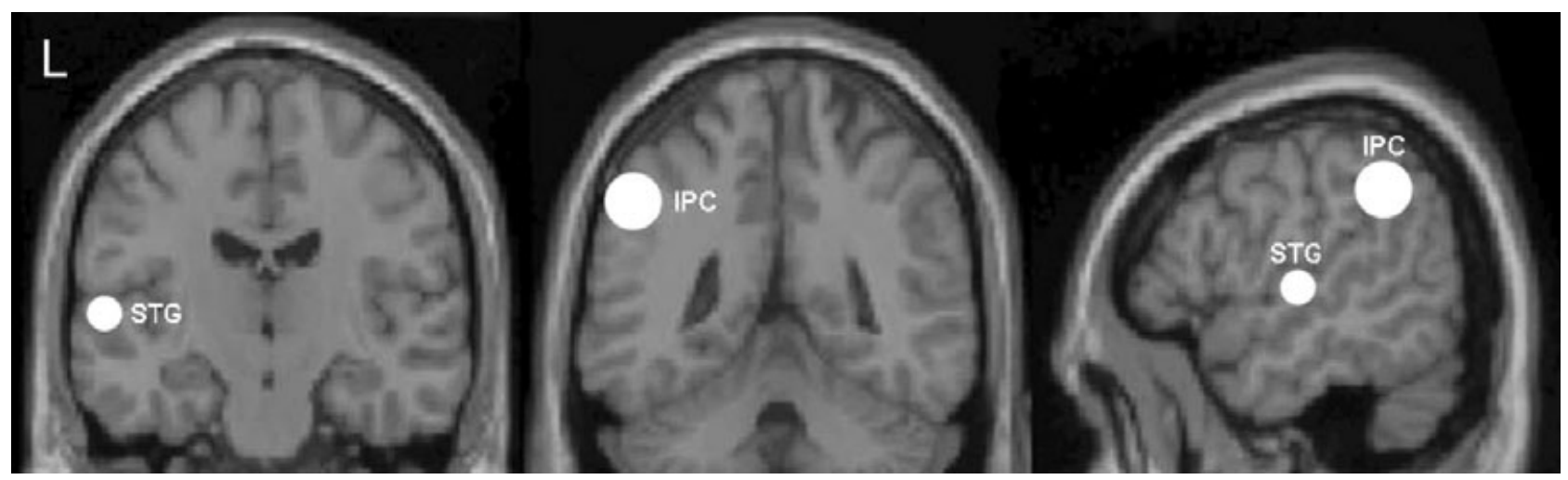

FIG. 1. The two regions of interest investigated with respect to left-right difference in literate and illiterate subjects. The inferior parietal region (IPC; BA 39 and 40; middle and right panels) was centred on $-55,-45,35 \mathrm{~mm}$ (Petersson et al., 1998) and the superior temporal region (STG; BA 22, 41 and 42; left and right panels) was centred on $-54,-16,+2 \mathrm{~mm}$. 
common for the older daughters of a family to be engaged in daily household activities at home and therefore they did not enter school. Later in life they may have started to work outside the family. In larger families, the younger children were generally sent to school when they reached the age of 6 or 7 years while the older siblings typically helped out with the younger siblings at home. Thus, the illiterate subjects we have investigated are illiterate for reasonably well-defined sociocultural reasons and not due to individual causes (e.g. learning difficulties or early central nervous system pathologies).

Literate and illiterate subjects live intermixed in this region of Portugal and participate actively in this community on similar terms. Illiteracy is not perceived as a functional handicap and the same sociocultural environment influences both literate and illiterate subjects to a similar degree. Some of the literate and illiterate subjects in our studies are from the same family, increasing the homogeneity in background variables. In addition, most of the literate subjects participating in our studies are not highly educated and typically they have had only $\sim 4$ years of schooling. In the present context, it is important to ensure that the subjects investigated are not cognitively impaired and also that the illiterate are matched to the literate subjects in as many relevant respects as possible, except of course for the consequences of not having had the opportunity to receive a formal education. In our studies we have attempted to match the different literacy groups in terms of several relevant variables, including for example age, gender, sociocultural background and level of everyday functionality (for a more detailed characterization of our study population and our selection procedures see Reis et al., 2003). These protocols and procedures ensure with reasonable confidence that the illiterate subjects are cognitively normal, that their lack of formal education results from specific sociocultural reasons and not because of low intelligence, learning disability, or other pathology potentially affecting the brain. The illiterate subjects and their literate controls included in our studies are similar along socioeconomic dimensions as well.

Twenty-eight participants (14 illiterate) were included in the study. The participants were classified as illiterate if they never had the opportunity to enter school and had no knowledge of reading and writing. They were matched along several sociocultural dimensions (Reis et al., 2003) and the overwhelming majority of the participants were working at home (Reis et al., 2003). School attendance was for 4 years in all literate participants except one ( 8 years; second sample). Participants were screened with structured sociocultural and medical health interviews and a short neuropsychological test battery (Reis et al., 2003). The sociocultural interview assessed occupation, literacy level (or, in case of being illiterate, the reasons for illiteracy) and the literacy level of the parents, in order to rule out any significant functional employment or daily life problems, learning disability, and problems acquiring reading and writing skills (literate subjects). The medical health interview was used to rule out any significant neurological, psychiatric or other diseases potentially involving the brain. The neuropsychological test battery for mental state assessment was used to exclude significant cognitive dysfunction. Subjects were also investigated with structural MRI to rule out any significant brain pathology. All participants lived active lives, were fully functional and were independently managing their every-day activities. In the first sample, 12 right-handed women were included (six literate, mean age $63 \pm 6$ years, 4 years of schooling; six illiterate, mean age $65 \pm 5$ years; age difference n.s.) and, in the second sample, 16 right-handed women (eight literate, mean age $58 \pm 6,4$ years of schooling; eight illiterate, mean age $63 \pm 5$ years; age difference n.s.). All subjects were assessed with a 14-item questionnaire adapted from the Edinburgh Inventory (Oldfield, 1971) with the response options right, left, or both. Questions such as "in which hand do you hold a book" or "... use a pen" were replaced with "which hand do you comb your hair with" and "... brush your teeth with". Subjects who were not strongly right-handed were excluded from the study and there were no group differences in terms of handedness for either of the two samples. The local Ethics and Radiation Safety committees at the Karolinska Hospital approved both studies. All subjects gave informed consent. Finally, we acquired high resolution T1-weighted structural MRI data in a third independent sample of 48 right-handed subjects (26 literate, mean age $68 \pm 6$ years, 4 years of schooling; 22 illiterate, mean age $70 \pm 6$ years; age difference n.s.). The local Ethics committee at Hospital Distrital de Faro approved the study. All subjects gave informed consent.

\section{Stimuli and experimental design}

For sample 1, lists of high-frequency three-syllable words were used (Petersson et al., 2000). Lists of pseudowords were constructed based on the words by changing the consonants whilst maintaining the vowels and the word length. Each list was presented at a sound level adjusted to the subjects' own preference, at a rate of one item per $6 \mathrm{~s}$. All participants were instructed to repeat either words or pseudowords during positron emission tomography (PET) scanning and to avoid any other type of speech production. The subjects practiced the paradigm until they performed satisfactorily. For sample 2, lists of word-pairs (12 pairs, common concrete one- to three-syllabic nouns, counterbalanced over subjects) were auditorily presented, with an interpair interval of $1300 \mathrm{~ms}$ and $500 \mathrm{~ms}$ between the words; half of the word-pairs were semantically and the other half phonologically related. The subject was instructed to silently listen to the word-pairs and memorize them. All subjects were scanned with their eyes closed.

\section{PET data acquisition and data analysis}

Scatter- and attenuation-corrected repeated measurements of regional cerebral blood flow (rCBF) were measured with a 3-D ECAT EXACT HR PET scanner and bolus injections of $\left[{ }^{15} \mathrm{O}\right]$ butanol $(>10 \mathrm{~min}$ between scans to ensure return to background). In sample 1, the PET images were preprocessed with the SPM package (http://www.fil. ion.ucl.ac.uk/spm): realigned, spatially normalized and transformed into a common stereotactic anatomical space as defined by the SPM PET template (a symmetric Montreal Neurological Institute template), 3-D isotropic Gaussian-filtered [16 mm full-width at half-maximum (FWHM)], and proportionally scaled to account for global confounds. Spherical regions of interest (Fig. 1; radius $15 \mathrm{~mm}$ ) were localized in the perisylvian parts of the inferior parietal cortex [Brodmann's areas (BA) 39 and 40], centred approximately at $x, y, z-55,-45,35 \mathrm{~mm}$ (see Fig. 1) and thus including the region corresponding to $\sim-45$ to $-65,-35$ to $-55,+25$ to $+45 \mathrm{~mm}$, using the Karolinska Computerized Brain Atlas (Greitz et al., 1991). The hemispheric left-right differences were then analysed in a random-effects model for words and pseudowords; as there was no interaction between conditions, literacy group, and left-right differences, the data were collapsed over the word and pseudoword condition. In sample 2, the PET data were acquired with the same protocol and similarly preprocessed with SPM using an isotropic Gaussian filter (14 mm FWHM). The general linear model was used to model rCBF data and the relevant contrast between flipped and unflipped PET images was generated for each subject and subjected to a random-effects analysis. The resulting statistical image was thresholded at $P=0.005$ and we tested for the nearest suprathreshold cluster to the region investigated in the first experiment, 
i.e. $(x, y, z)-55,-45,+35 \mathrm{~mm}$ (Friston, 1997; Worsley, 2003). In order to further characterize the regional activation levels in the inferior parietal region we used the volume-of-interest tool in SPM to extract $\mathrm{rCBF}$ data from spherical regions of interest (radius $15 \mathrm{~mm}$ ) and generated the relevant mean and SEM activation levels. In order to test the specificity of our results with respect to the inferior parietal cortex, we also investigated the superior temporal region (BA 22, 41 and 42), as it has been shown that this region is already left-lateralized in infants (Dehaene-Lambertz et al., 2002). The same procedure was used to extract rCBF data from the middle part of the superior temporal cortex (BA 22, 41 and 42; $x, y, z-54,-16,+2 \mathrm{~mm}$; radius $6 \mathrm{~mm})$. The $P$-values reported were corrected for multiple nonindependent comparisons based family-wise error (FWE-corrected) and smooth random-field theory (Worsley et al., 1996).

\section{MRI data acquisition and data analysis}

High-resolution T1-weighted 3-D Multi-planar gradient recalled structural images were acquired with a Philips $1.5 \mathrm{~T}$ Intera wholebody scanner (TE, $3.93 \mathrm{~ms}$; flip angle, $10^{\circ}$; slice matrix, $256 \times 256$; field of view, $256 \mathrm{~mm}$; 132 axial slices; slice thickness, $1.0 \mathrm{~mm}$, voxel size, $1 \mathrm{~mm}^{3}$ ). The structural images were transformed from Dicom to Analyse format with MRIcro (www.sph.sc.edu/comd/rorden/mricro. html) and subsequently processed in SPM. We used the optimized modulated voxel-based morphometry protocol to investigate the grey and white matter in the two literacy groups (Good et al., 2002; Ashburner \& Friston, 2004, 2005; Mechelli et al., 2005). Briefly, customized grey and white matter and cerebral spinal fluid templates were created from the study group (48 subjects). This involved spatially normalizing all the structural scans to the SPM T1 template, segmenting each normalized image into grey and white matter and cerebrospinal fluid (CSF) compartments, and smoothing each greyand white-matter segment with an isotropic 3-D Gaussian filter kernel ( $8 \mathrm{~mm}$ FWHM). Finally, all the filtered segments were averaged to create grey and white matter and CSF templates. The original structural images of the subjects were normalized to the T1 template and segmented using the prior images previously created. To account for changes in the absolute volume of grey and white matter during spatial normalization, the normalized images were modulated with their respective Jacobian image. Finally, all segmented images for each subject were spatially filtered with an isotropic 3-D Gaussian kernel (12 mm FWHM) and group comparisons of grey and white matter were conducted with SPM in a random-effects analysis based on a two-sample $t$-test and smooth random field theory (thresholded at $P=0.005$; Worsley et al., 1996) with age as a covariate of no interest. The $P$-values reported were corrected for multiple nonindependent comparisons (FWE-corrected) based on the estimated nonstationary (i.e. nonisotropic) statistical smoothness of the residual images.

\section{Results}

\section{Background behavioural and functional neuroimaging results}

The basic behavioural and functional neuroimaging results of the first study are reported in Petersson et al. (2000) and Castro-Caldas et al. (1998; see also Petersson \& Reis, 2006; Petersson et al., 2001; Reis \& Castro-Caldas, 1997). The behavioural results of the second study were as follows. Subsequent to listening to lists of word pairs, the subjects were tested with a cued-recall test. The literate performed better than the illiterate subjects on both tasks (semantic word pairs: literate, $73 \%$ correct, illiterate, $53 \%$ correct; Mann-Whitney $U$-test, $P<0.01$; phonological word pairs: literate, $60 \%$; illiterate, $25 \%$;
Mann-Whitney $U$-test, $P<0.01)$ and both groups performed better on semantic than on phonological word pairs (Wilcoxon matched-pairs test, $P<0.05)$. The basic functional neuroimaging results of the second study were as follows. Comparing listening to and encoding word pairs to rest (eyes closed) in both groups yielded a typical verbal working memory network including significant activations in: left anterior cingulate cortex, left inferior frontal gyrus and frontal operculum, inferior parts of the frontal poles bilaterally, bilateral inferior and superior parietal lobules, bilateral parietotemporal junction and temporal lobes extending into the temporal poles, and the thalamus and cerebellum bilaterally. The results were very similar when broken down on semantic and phonological word pairs. The literate group showed significantly greater activity (FWE-corrected for the whole brain) than did the illiterate in the left frontopolar region (BA 10; cluster $P=0.02$ ), the left inferior parietal and parietotemporal region (BA 39, 40 and 22; cluster $P<0.001$ ), left inferior temporal lobes extending into the temporal poles (BA 20, 21 and 38; cluster $P=0.08$ ), the precuneus (BA 7; cluster $P<0.001$ ) and the right mediolateral cerebellum $(P=0.04)$. In the reverse comparison, the illiterate showed significantly greater activity in the anterior cingulate cortex (BA 32; cluster $P<0.001$ ), the frontal operculum and anterior insula bilaterally (BA 47 and 49 and BA 13 and 15; left cluster $P=0.01$ and right cluster $P<0.001$ ), and in the right inferior parietal and parietotemporal region (BA 39, 40 and 22; cluster $P<0.001)$. The group differences observed in the semantic and phonologic conditions were essentially similar [group $\times$ condition interaction, nonsignificant $(P=0.75)]$. These results were independent of age (actually they improved somewhat by considering age as a covariate of no interest). Overall, the results reported above are consistent with the results from the investigation of the left-right difference in the two literacy groups.

\section{Functional left-right differences between literate and illiterate subjects}

With respect to the main objective of the current investigation, the left-right comparison in the first sample (Petersson et al., 1998) showed a significant group difference (group $\times$ hemisphere interaction, $P=0.009$ ), which showed a positive left-right difference in the literate group while the illiterate subjects showed a negative left-right difference. The group $\times$ hemisphere interaction was independent (group $\times$ condition interaction, n.s.) of whether the subjects repeated words $(P=0.017$; Fig. 2a, left panel) or pseudowords $(P=0.006$; Fig. 2a, right panel).

In the second sample, in which the subjects listened to and encoded word pairs, we examined whether the findings from the first study could be replicated in an independent sample of the two literacy groups. We thus tested for between-group left-right differences in the suprathreshold cluster nearest to the region investigated in the first experiment and observed a significant inferior parietal cluster (BA 39 and 40, group $\times$ hemisphere interaction, $P=0.029$, FWE-corrected; local maximum at $-60,-44,+38 \mathrm{~mm}, P=0.013$, FWE-corrected). Again, the group $\times$ hemisphere interaction was independent (group $\times$ condition interaction, n.s.) of whether the subjects listened to semantically-related word pairs (BA 39 and 40, cluster $P=0.015$; local maximum at $-64,-42,+36 \mathrm{~mm}, P=0.009$, FWE-corrected; Fig. $2 \mathrm{~b}$, left panel) or phonologically-related word pairs (BA 39 and 40, cluster $P=0.005$; local maximum at $-52,-44,+40 \mathrm{~mm}, P=0.005$, FWE-corrected; Fig. 2b, right panel). Thus, the literate group showed a positive functional left-right difference while the illiterate subjects tended to show a negative left-right difference in the inferior parietal region extending towards the temporoparietal junction (Fig. 3). 

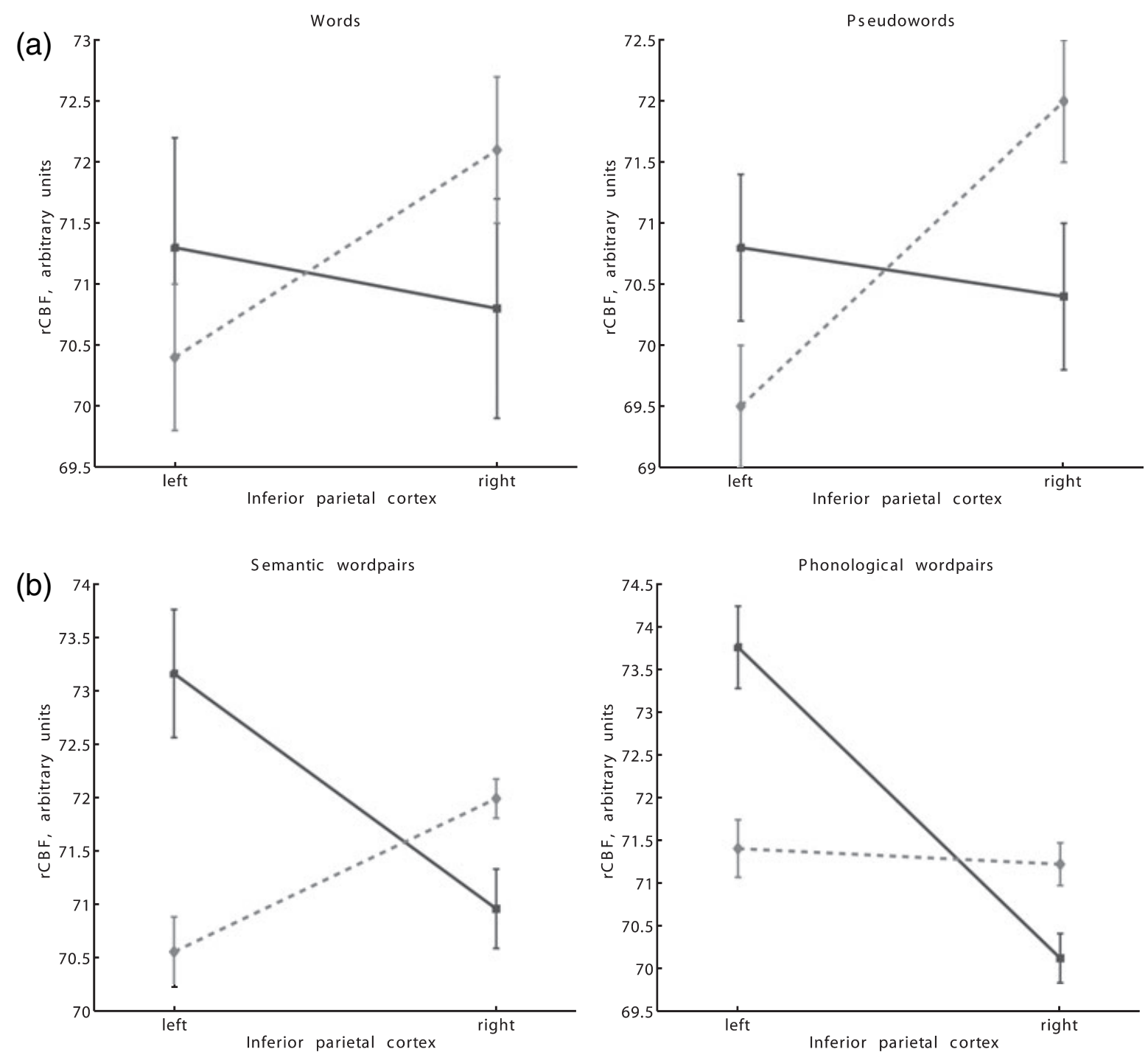

FIG. 2. Task-related activation levels (rCBF, arbitrary units; mean $\pm \mathrm{SE}$ ) in the left and right inferior parietal region (BA 39 and 40 ). (a) Experiment 1. The literate group (solid lines) showed a positive left-right difference while the illiterate group (dashed lines) showed a negative left-right difference for both words and pseudowords (upper left and right panel). (b) Experiment 2. The literate group (solid lines) showed a positive left-right difference, while the illiterate group (dashed lines) showed a negative or no left-right difference for semantic and phonological word pairs (lower left and right panels).

Age was a controlled factor in the present study and there were no significant differences in age between groups in either of the samples. However, the mean age differed in the second sample by $\sim 5$ years so, in order to exclude this as a potential confound, we reanalysed the data with age as a covariate of no interest. This improved the results somewhat (Fig. 3), suggesting that age, if anything, contributes some noise with respect to the effects we are reporting here. In this reanalysis, we observed the same left-right differences in the inferior parietal cortex independent of condition (BA 39 and 40, cluster $P=0.001$, FWE-corrected for the whole brain: semantic, cluster $P=0.01$; phonological, cluster $P=0.007$, FWE-corrected). This inferior parietal cluster [local maxima at $(-54,-58,52),(-48,-60$, $42)$, and $(-54,-42,36)]$ included the temporo-parietal region [BA $22 / 39 / 40$; local maxima at $(-68,-50,26),(-52,-52,22),(-66$, $-54,10)]$ extending downwards to the occipito-temporal cortex [BA $19,20$ and 37; local maximum at $(-52,-60,-10)]$. Investigating the inferior parietal region of interest we observed local maxima at -54 , $-42,+36 \mathrm{~mm}$ (BA 39 and 40, $P=0.001$, FWE-corrected; cluster $P=0.001$, FWE-corrected), and segregated on semantically- (BA 39 and 40, cluster $P=0.016$; local maximum at $-56,-42,36 \mathrm{~mm}$, $P=0.036$, FWE-corrected) and phonologically-related word pairs (BA 39 and 40, cluster $P=0.007$; local maximum at $-54,-44$, $34 \mathrm{~mm}, P=0.021$, FWE-corrected). In addition, we observed a significant posterior inferior-middle temporal cluster (BA 20 and 37, $P=0.07$, with a local maximum at $-68,-30,-22 \mathrm{~mm}, P=0.03$, FWE-corrected for the whole brain), which was similarly expressed for semantic and phonological word pairs. It has been suggested that infants are left-lateralized in the superior temporal gyrus when listening to speech or speech-like sounds (Dehaene-Lambertz et al., 2002). This would suggest that the two literacy groups should show a similar degree of left-right difference in this region and, in order to test the specificity of our results with respect to the inferior parietal region, we investigated the left-right differences in the superior temporal region (BA 22, 41 and 42). The results showed the same degree of left-right difference in the two literacy groups in both sample (group comparisons in both samples, n.s.) suggesting that early speech-related brain regions are not functionally modulated by literacy in the way that the inferior parietal region is. 

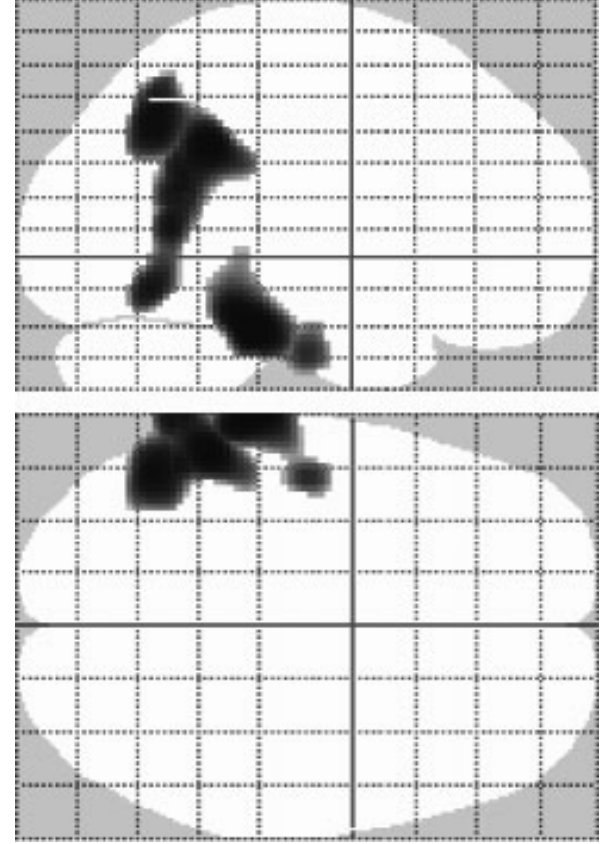

FIG. 3. Whole-brain analysis of the left-right differences between literacy groups with age as a covariate of no interest. The inferior parietal and parietotemporal region showed greater left-right difference in the literate than in the illiterate group (BA 39 and 40, cluster $P=0.001$, FWE-corrected for the whole brain; semantic, cluster $P=0.01$; phonological, cluster $P=0.007$, FWE-corrected). In addition, there was a significant posterior inferior temporal cluster [BA 20 and 37, $P=0.07$; with a local maximum at $(-68,-30,-22)$, $P=0.03$. FWE-corrected for the whole brain].

Finally, in order to make the connection with our previous structural results related to the corpus callosum more suggestive (Castro-Caldas et al., 1999), we report here the results of the VBM analysis with respect to the corpus callosum and the inferior parietal regions (the complete results will be reported elsewhere). With respect to white matter, we first investigated the corpus callosum based on previously reported results suggesting that the corpus callosum of literate subjects is thicker than that of illiterate subjects in the posterior third of the mid-body region (Castro-Caldas et al., 1999). We placed a spherical region of interest (radius $10 \mathrm{~mm}$ ) centred on $0,-20,24 \mathrm{~mm}$ in the

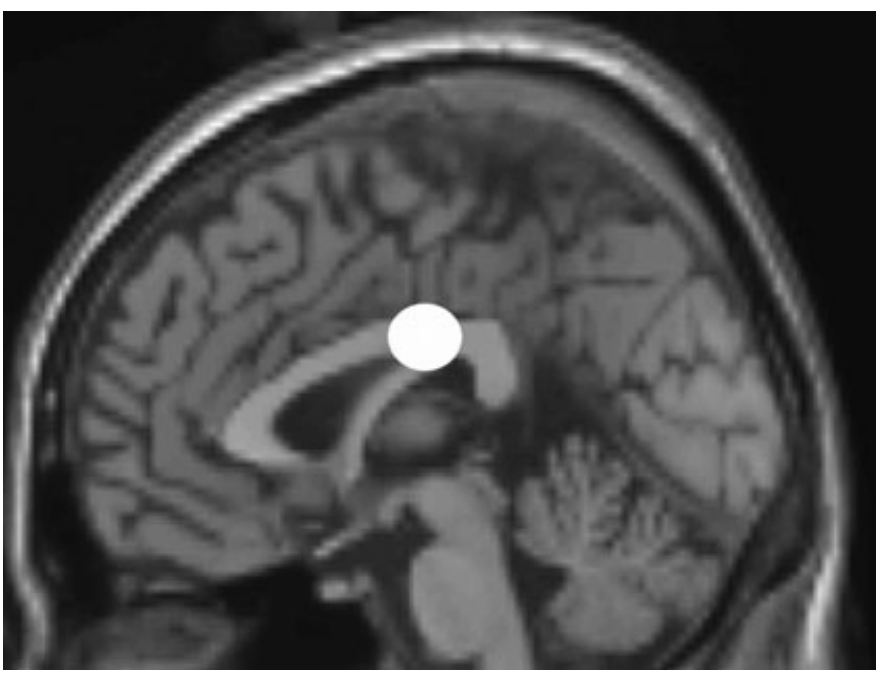

FIG. 4. The region of interest in the posterior third of the mid-body region of the corpus callosum. This part of the corpus callosum was investigated with a spherical region centred on $0,-20,+25 \mathrm{~mm}$, based on previous findings suggesting that this region is significantly thicker in literate than in illiterate subjects (Castro-Caldas et al., 1999).

posterior third of the mid-body region of the corpus callosum (Fig. 4). We observed significantly greater white matter intensity in the literate than in the illiterate group (cluster $P=0.02$, with local maximum at $+6,-19,+24 \mathrm{~mm} ; P=0.04$, FWE-corrected). This cluster was part of a larger significant white matter cluster $(P=0.002$, FWE-corrected for the whole brain) which extended towards the white matter underlying the inferior parietal and parietotemporal regions, bilaterally (Fig. 5). There were no significant differences between the two literacy groups in the reverse comparison, nor was there any difference in grey matter intensity between literacy groups in the vicinity of the inferior parietal regions or the corpus callosum.

\section{Discussion}

The results from two independent samples performing simple auditory-verbal language tasks suggest that literate subjects are relatively left-lateralized compared to illiterate subjects. Thus, it

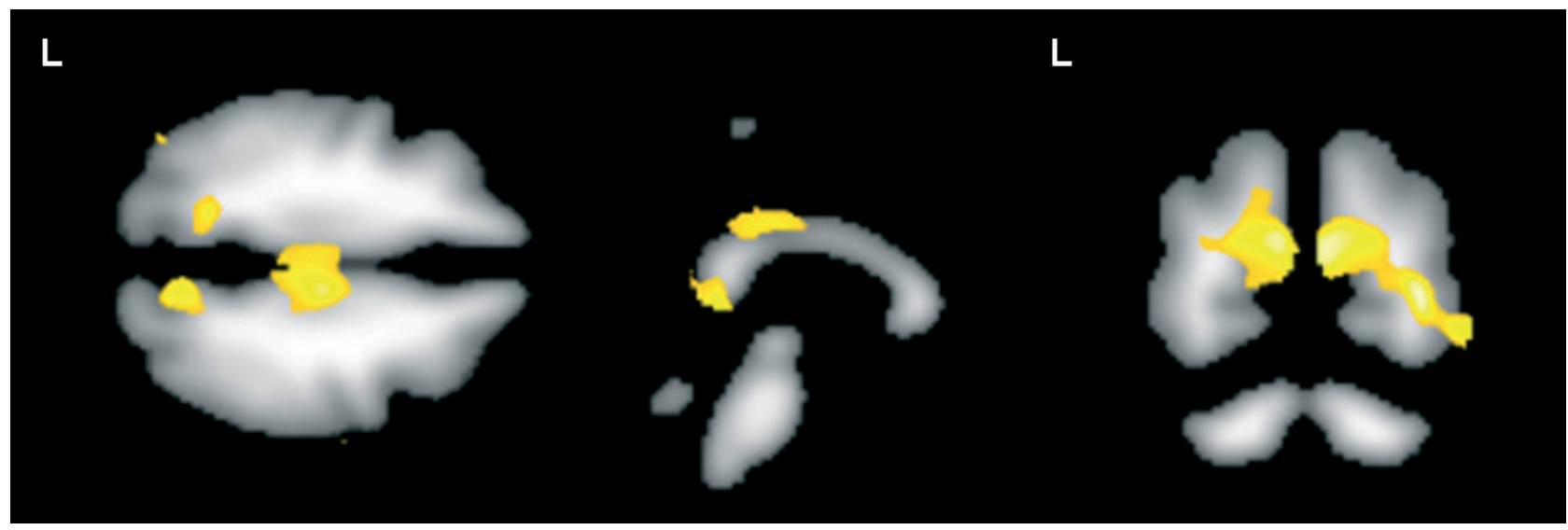

FIG. 5. Experiment 3: we observed significantly greater white matter density in the literate than in the illiterate group in the posterior third of the mid-body region of the corpus callosum (left and mid panels). This cluster was part of a larger white-matter cluster extending into the white matter underlying the inferior parietal/parieto-temporal regions bilaterally (right panel, coronal section at $y=50$ ). There were no significant differences in the reverse comparison. 
appears that literacy influences the functional balance between the left and right inferior parietal region. Our previous investigations of this southern Portuguese population have shown that the acquisition of reading and writing skills influences aspects of the auditory-verbal language system (Petersson et al., 2000). In particular, previous results have shown that there are differences in verbal working memory capacity between literate and illiterate individuals (for reviews see Petersson et al., 2001, in press; Petersson \& Reis, 2006) and corresponding differences in phonological loop interactions related to the inferior parietal cortex between the literacy groups (Petersson et al., 2000). Moreover, it has been suggested that the phonological loop might serve as a language learning device with an integral role in the systems for spoken and written language acquisition (Baddeley et al., 1998), and aspects of sublexical phonological processing appear to differentiate the two literacy groups (Morais, 1993; Petersson et al., 2001; Petersson \& Reis, 2006). This is most prominently expressed in terms of phonological awareness, the most well-accepted difference between schooled and unschooled individuals that does not depend on educational level as such (Coppens et al., 1998; Kosmidis et al., 2006).

Grey and white matter differences were investigated with VBM in a third sample of literate and illiterate subjects. The VBM analysis showed a significant white-matter difference in the posterior third of the mid-body region of the corpus callosum, replicating the findings of Castro-Caldas et al. (1999), and this difference was part of a larger white-matter cluster that extended towards the white matter underlying the inferior parietal and parietotemporal regions, bilaterally. There was no group difference with respect to local grey-matter intensity in the vicinity of the corpus callosum or the inferior parietal regions. It is interesting to note that recent experimental findings have indicated a rostral to caudal myelination process of the corpus callosum during childhood and early adulthood (Thompson et al., 2000). This suggests an ongoing developmental process to establish coordination and efficient interactions between the two hemispheres at least until early adulthood. The fibres that cross over in the posterior mid-body region of corpus callosum interconnect the parietotemporal regions and undergo extensive myelination during the typical years of reading acquisition (i.e. 6-10 years of age; Thompson et al., 2000). The posterior mid-body region of corpus callosum is the region in which previous evidence suggest that the corpus callosum of literate subjects are thicker than that of illiterate subjects (Castro-Caldas et al., 1999), a finding replicated in the present study. Moreover, the literate individuals in our study population acquire reading and writing skills during 6-10 years of age. One may therefore speculate that acquiring reading and writing skills at the appropriate age shapes not only the morphology of the corpus callosum and the corresponding interhemispheric connectivity but also the pattern of interaction between the interconnected inferior parietal regions. Thus there might be a causal connection between reading and writing acquisition, the development of the corpus callosum, and the hemispheric differences reported in this study. This would suggest that there is an active process of functional reconfiguration of the role of the left and right inferior parietal cortex as well as their interaction via the relevant parts of the corpus callosum.

One possibility that cannot be addressed in the present study, which is based on comparing anatomically homotopic regions, is that the functionally relevant regions are not anatomically colocalized in the two literacy groups. However, the present findings would then indirectly reflect this underlying hemispheric difference between the literacy groups. Another issue is whether the present results reflect the direct effects of acquiring reading and writing skills or reflect cumulative life-span effects. One way of addressing this is to investigate the functional interaction between the left and right inferior parietal regions in preliterate and literate children. Furthermore, recent evidence suggests that genetic factors also significantly influence the local grey-matter distribution in language-related regions, and more so in left than right hemispheric language regions (Thompson et al., 2001). It should be emphasized that reading and writing skills are learned cognitive capacities of a different kind than natural language per se, the latter being a human universal, acquired by all normal humans in a largely spontaneous unsupervised fashion. Finally, it is possible that the literate and illiterate participants performed the various tasks differently, in ways that rely differently on the right and left inferior parietal regions. It is in principle conceivable that the two literacy groups engage in different types of cognitive processing in solving the tasks investigated in this study. For example, the literate subjects might rely on pure language processing when listening to word pairs while the illiterate subjects engage in visual imagination or visual-spatial processing. First, if this is indeed the case then this would perhaps translate into a more prominent left-right difference for semantically-related than for phonologically-related word-pairs. However, the results were basically similar in this respect. Second, it seems less likely that any of the literacy groups would engage to any significant degree in visual imagination or visualspatial processing during immediate verbal repetition of pseudowords. Instead, the main finding of this study is that the inferior parietal leftright differences are relatively independent of the lexical tasks investigated. A more likely functional explanation is related to differences in verbal working memory between literacy groups, and fundamentally of course to the acquisition of reading and writing skills. The inferior parietal region has been related to both reading (Friedman et al., 1993; Horwitz et al., 1998; Shaywitz et al., 1998; Paulesu et al., 2000) and to verbal working memory (Baddeley, 2003; Vallar \& Papagno, 1995; Baddeley et al., 1998; Jonides et al., 1998; Becker et al., 1999). We have previously shown that there are differences in phonological loop interactions between literate and illiterate subjects related to the inferior parietal cortex (Petersson et al., 2000), a region hypothesized to support the phonological store (Becker et al., 1999), and there are corresponding behavioural findings related to verbal working memory (for reviews see e.g. Petersson et al., 2001, in press; Petersson \& Reis, 2006). However, a detailed understanding of the mechanisms behind these differences is still not fully understood.

In conclusion, the present results provided evidence that a cultural factor, literacy, influences the functional hemispheric balance in the inferior parietal and parieto-temporal region and we observed parallel differences in the white matter related to the mid-body region of the corpus callosum and the inferior parietal and parietotemporal regions. There was no corresponding difference in the local grey matter intensity in the vicinity of these structures. This suggests that the influence of literacy on brain structure related to reading and verbal working memory is affecting large-scale brain connectivity more than grey matter per se.

\section{Acknowledgements}

This work was supported in part by Fundação para a Ciência e Tecnologia (FCT/POCTI/46955/PSI/2002), EU grant QLK6-CT-99-02140, the Swedish Medical Research council $(8276,127169)$, the Knut and Alice Wallenberg Foundation and the Swedish Dyslexia Foundation Association. We thank Professor Dr Peter Hagoort, Professor Dr Guillen Fernandez, Dr Ivan Toni, Dr Sandra Vos, Dr Marcel Bastiaansen and Dr Oliver Mueller for comments on earlier versions of this paper. We also want to thank Simon Askelöf for help with data logistics and statistical analyses related to the first experiment as well as Paulo Tinoco and Lambertine Tackenberg at Clinica Fernando Sancho, Faro, Portugal, for their help with the structural MRI data acquisition. 


\section{Abbreviations}

BA, Brodmann's area; FWE-corrected, corrected for multiple nonindependent comparisons based on family-wise error; FWHM, full-width at half-maximum MRI, magnetic resonance imaging; PET, positron emission tomography; rCBF, regional cerebral blood flow; VBM, voxel-based morphometry.

\section{References}

Abadzi, H. (2003) Improving Adult Literacy Outcomes: Lessons from Cognitive Research for Developing Countries. The World Bank Operation Evaluation Department, Washington, DC.

Aboitiz, F., Ide, A. \& Olivares, R. (2003) Corpus callosum morphology in relation to cerebral asymmetries in the postmortem human. In Zaidel, E. \& Iacoboni, M. (eds), The Parallel Brain: the Cognitive Neuroscience of the Corpus Callosum. MIT Press, Cambridge, MA, pp. 33-46.

Ashburner, J. \& Friston, K.J. (2004) Computational neuroanatomy. In Frackowiak, R.S.J., Friston, K.J., Frith, C., Dolan, R., Price, C., Zeki, S., Ashburner, J. \& Penny, W. (eds), Human Brain Function. Academic Press, San Diego, CA, pp. 635-724.

Ashburner, J. \& Friston, K.J. (2005) Unified segmentation. Neuroimage, 26, 839-851.

Baddeley, A. (2003) Working memory: Looking back and looking forward. Nat. Rev. Neurosci., 4, 829-839.

Baddeley, A., Gathercole, S. \& Papagno, C. (1998) The phonological loop as a language learning device. Psychol. Rev., 105, 158-173.

Becker, J.T., MacAndrew, D.K. \& Fiez, J.A. (1999) A comment on the functional localization of the phonological storage subsystem of working memory. Brain Cognition, 41, 27-38.

Cameron, R.F., Currier, R.D. \& Haerer, A.F. (1971) Aphasia and literacy. Br. J. Disorders Comm., 6, 161-163.

Castro-Caldas, A., Miranda Cavaleiro, P., Carmo, I., Reis, A., Leote, F., Ribeiro, C. \& Ducla-Soares, E. (1999) Influence of learning to read and write on the morphology of the corpus callosum. Eur. J. Neurol., 6, $23-28$.

Castro-Caldas, A., Peterson, K.M., Reis, A., Stone-Elander, S. \& Ingvar, M. (1998) The illiterate brain: Learning to read and write during childhood influences the functional organisation of the adult brain. Brain, 121, 1053-1063.

Coppens, P., Parente, M.A.M.P. \& Lecours, A.R. (1998) Aphasia in illiterate individuals. In Coppens, P., Lebrun, Y. \& Basso, A. (eds), Aphasia in Atypical Populations. Lawrence Erlbaum, London, pp. 175-202.

Damásio, H., Damásio, A.R., Castro-Caldas, A. \& Hamsher, K.S. (1979) Reversal of ear advantage for phonetically similar words in illiterates. J. Clin Neuropsychol., 1, 331-338.

De Lacoste, M.C., Kirkpatrick, J.B. \& Ross, E.D. (1985) Topography of the human corpus callosum. J. Neuropath. Exp. Neurol., 44, 578-591.

Dehaene-Lambertz, G., Dehaene, S. \& Hertz-Pannier, L. (2002) Functional neuroimaging of speech perception in infants. Science, 298, 2013-2015.

Friederici, A.D. (2002) Towards a neural basis of auditory sentence processing. Trends Cogn. Sci., 6, 78-84

Friedman, R.F., Ween, J.E. \& Albert, M.L. (1993) Alexia. In Heilman, K.M. \& Valenstein, E. (eds), Clinical Neuropsychology, 3rd edn. Oxford University Press, New York, pp. 37-62.

Friston, K.J. (1997) Testing for anatomically specified regional effects. Hum. Brain Mapp., 5, 133-136.

Gombert, J.E. (2003) Implicit and explicit learning to read: Implication as for subtypes of dyslexia. Current Psychology Letters: Behavior, Brain and Cognition, 10, [on line].

Good, C.D., Scahill, R.I., Fox, N.C., Ashburner, J., Friston, K.J., Chan, D., Crum, W.R., Rossor, M.N. \& Frackowiak, R.S.J. (2002) Automatic differentiation of anatomical patterns in the human brain: validation with studies of degenerative dementias. Neuroimage, 17, 29-46.

Greitz, T., Bohm, C., Holte, S. \& Eriksson, L. (1991) A computerized brain atlas: Construction, anatomical content and some applications. J. Comput. Assist. Tomogr., 15, 26-38.

Horwitz, B., Rumsey, J.M. \& Donohue, B.C. (1998) Functional connectivity of the angular gyrus in normal reading and dyslexia. Proc. Natl. Acad. Sci. USA, 95, 8939-8944.

Jonides, J., Schumancher, E.H., Smith, E.E., Koeppe, R.A., Awh, E., ReurterLorenz, P.A., Marchuetz, C. \& Willis, C.R. (1998) The role of parietal cortex in verbal working memory. $J$. Neurosci., 18, 5026-5034.

Josse, G. \& Tzourio-Mazoyer, N. (2004) Hemispheric specialization for language. Brain Res. Rev., 44, 1-12.
Karmiloff-Smith, A., Grant, J., Sims, K., Jones, M.C. \& Cuckle, P. (1996) Rethinking metalinguistic awareness: representing and accessing knowledge about what counts as a word. Cognition, 58, 197-219.

Kelley, W.M., Miezin, F.M., McDermott, K.B., Buckner, R.L., Raichle, M.E., Cohen, N.J., Ollinger, J.M., Akbudak, E., Conturo, T.E., Snyder, A.Z. \& Peterson, S.E. (1998) Hemispheric specialization in human dorsal frontal cortex and medial temporal lobe for verbal and nonverbal memory encoding. Neuron, 20, 927-936.

Knecht, S., Floel, A., Drager, B., Breitestein, C., Sommer, J., Henningsen, H., Ringelstein, E.B. \& Pascual-Leone, A. (2002) Degrees of language lateralization determine susceptibility to unilateral brain lesions. Nat. Neurosci., 5, 695-699.

Kosmidis, M.H., Tsapkini, K. \& Folia, V. (2006) Lexical processing in illiteracy: Effect of literacy or education? Cortex, 42, 1021-1027.

Lecours, A.R. (1989) Literacy and acquired aphasia. In: Galaburda, A.M. (ed.), From Reading to Neurons. MIT Press, Cambridge, MA, pp. 27-39.

Mechelli, A., Price, C.J., Friston, K.J. \& Ashburner, J. (2005) Voxel-based morphometry of the human brain: Methods and applications. Curr. Med. Imaging Rev., 1, 105-113.

Morais, J. (1993) Phonemic awareness, language and literacy. In Joshi, R.M. \& Leong, C.K. (eds), Reading Disabilities: Diagnosis and Component Processes, Kluwer Academic Publishers, Dordrecht, NL, pp. 175-184.

Oldfield, R.C. (1971) The assessment and analysis of handedness: the Edinburgh inventory. Neuropsychologia, 9, 97-113.

Pandya, D.N., Karol, E.A. \& Heilbronn, D. (1971) The topographical distribution of interhemispheric projections in the corpus callosum of the rhesus monkey. Brain Res., 32, 31-43.

Pandya, D.N. \& Seltzer, B. (1986) The topography of commmisural fibers In Lepore, F., Ptito, M. \& Jaspar, H. (eds), Two Hemispheres - One Brain: Functions of the Corpus Callossum. Alan R. Liss, New York, pp. 47-73.

Paulesu, E., McCrory, E., Fazio, F., Menoncello, L., Brunswick, N., Cappa, S.F., Cotelli, M., Cossu, G., Corte, F., Lorusso, M., Pesenti, S., Gallagher, A., Perani, D., Price, C., Frith, C.D. \& Frith, U. (2000) A cultural effect on brain function. Nat. Neurosci., 3, 91-96.

Petersson, K.M. (2005) Learning and Memory in the Human Brain. Karolinska University Press, Stockholm.

Petersson, K.M., Ingvar, M. \& Reis, A. (in press) Language and literacy from a cognitive neuroscience perspective. In Olson, D.R. \& Torrence, N. (eds), Cambridge Handbook of Literacy. Cambridge University Press, New York, in press.

Petersson, K.M. \& Reis, A. (2006) Characteristics of illiterate and literate cognitive processing: Implications for brain-behavior co-constructivism. In Baltes, P.B., Rösler, F. \& Reuter-Lorenz, P.A. (eds), Lifespan Development and the Brain: the Perspective of Biocultural Co-Constructivism, Cambridge University Press, New York, pp. 279-305.

Petersson, K.M., Reis, A., Askelöf, S., Castro-Caldas, A. \& Ingvar, M. (1998) Differences in inter-hemispheric interactions between literate and illiterate subjects during verbal repetition. Neuroimage, 7, S217.

Petersson, K.M., Reis, A., Askelöf, S., Castro-Caldas, A. \& Ingvar, M. (2000) Language processing modulated by literacy: a network-analysis of verbal repetition in literate and illiterate subjects. J. Cogn. Neurosci., 12, 364-382.

Petersson, K.M., Reis, A. \& Ingvar, M. (2001) Cognitive processing in literate and illiterate subjects: a review of some recent behavioral and functional data. Scand. J. Psychol., 42, 251-167.

Reggia, J.A. \& Schulz, R. (2002) The role of computational modeling in understanding hemispheric interactions and specialization. Cogn. System Res., 3, 87-94.

Reis, A. \& Castro-Caldas, A. (1997) Illiteracy: a bias for cognitive development. J. Int. Neuropsychol. Soc., 3, 444-450.

Reis, A., Guerreiro, M. \& Petersson, K.M. (2003) A socio-demographic and neuropsychological characterization of an illiterate population. Appl. Neuropsychol., 10, 191-204.

Shaywitz, S.E., Shaywitz, B.A., Pugh, K.R., Fulbright, R.K., Constable, R.T., Mencl, W.E., Shankweiler, D.P., Liberman, A.M., Skudlarski, P., Fletcher, J.M., Katz, L., Marchione, K.E., Lacaide, C., Gatenby, C. \& Gore, J.C. (1998) Functional disruption in the organization of the brain for reading in dyslexia. Proc. Natl. Acad. Sci. USA, 95, 2636-2641.

Sommer, I.E.C., Ramsey, N.F., Mandl, R.C.W. \& Kahn, R.S. (2002) Language lateralization in monozygotic twin pairs concordant and discordant for handedness. Brain, 125, 2710-2718.

Stephan, K.E., Marshall, J.C., Friston, K.J., Rowe, J.B., Ritzl, A., Zilles, K. \& Fink, G.R. (2003) Lateralized cognitive processes and lateralized task control in the human brain. Science, 301, 384-386. 
Thompson, P.M., Cannon, T.D., Narr, K.L., van Erp, T., Poutanen, V.P., Huttunen, M., Lonnqvist, J., Standertskjold-Nordenstam, C. G., Kaprio, J., Khaledy, M., Dail, R., Zoumalan, C.I. \& Toga, A.W. (2001) Genetic influences on brain structure. Nat. Neurosci., 4, 1253-1258.

Thompson, P.M., Giedd, J.N., Woods, R.P., MacDonald, D., Evans, A.C. \& Toga, A.W. (2000) Growth patterns in the developing brain detected by using continuum mechanical tensor maps. Nature, 404, 190-193.

Vallar, G. \& Papagno, C. (1995) Neuropsychological impairments of short-term memory. In Baddeley, A.D., Wilson, B.A. \& Watts, F.N., (Eds), Handbook of Memory Disorders. Wiley, New York.

Wechsler, A.F. (1976) Crossed aphasia in an illiterate dextral. Brain Language, 3, 164-172.
Worsley, K.J. (2003) Developments in random field theory. In Frackowiak, R.S.J., Friston, K.J., Frith, C., Dolan, R., Price, C., Zeki, S., Ashburner, J. \& Penny, W. (eds), Human Brain Function (2nd edn). Academic Press, San Diego, CA, pp. 881-886.

Worsley, K.J., Marrett, S., Neelin, P., Vandal, A.C., Friston, K.J. \& Evans, A.C. (1996) A unified statistical approach for determining significant signals in images of cerebral activation. Hum. Brain Mapp., 4, 58-73.

Zaidel, E. \& Iacoboni, M. (2003) . The Parallel Brain: the Cognitive Neuroscience of the Corpus Callosum (section: Anatomy and morphometry of the corpus callosum). MIT Press, Cambridge, MA, pp. 9-136.

Ziegler, J.C. \& Goswami, U. (2005) Reading acquisition, developmental dyslexia, and skilled reading across languages: a psycholinguistic grain size theory. Psychol Bull., 131, 3-29. 